\title{
Quão móveis somos? O New Mobilities Paradigm em questão
}

\author{
How movable are we? The New Mobilities Paradigm in question
}

\author{
José Diego Gobbo Alves \\ Geógrafo e Doutorando do PPG em Ambiente e \\ Sociedade (NEPAM/Unicamp), Brasil \\ jdgobboalves@gmail.com \\ Álvaro de Oliveira D'Antona \\ Doutor em Ciências Sociais e Livre-docente na Faculdade de \\ Ciências Aplicadas (Unicamp), Brasil \\ alvaro.dantona@fca.unicamp.br \\ Eduardo José Marandola Junior \\ Doutor em Geografia e Livre-docente na Faculdade de \\ Ciências Aplicadas (Unicamp), Brasil \\ eduardo.marandola@,fca.unicamp.br
}

\begin{abstract}
Resumo
Com base no paradigma das mobilidades (The new mobilities paradigm) o artigo discorre sobre as formas de mobilidades brasileira destacando as suas dimensões espaciais. Foi realizado um levantamento bibliográfico dos principais autores que discutem a temática a partir do referido paradigma, buscando destacar a dimensão espacial das práticas de mobilidades. Tal reflexão é articulada aos dados dos Censos Demográficos de 2000 e 2010 e de outras fontes, explicitando padrões e formas de mobilidades existentes no país. Os resultados apontam um aumento nas formas de mobilidades entre 2000 e 2010 e um conjunto de fixos territoriais que viabilizam as mobilidades virtual e imaginária, conectando lugares e pessoas espacialmente distantes, o que torna possível estabelecer comparações do caso brasileiro com outros contextos socioespaciais. Ao trazer à luz o paradigma das mobilidades, ainda pouco explorado no Brasil, destacamos a sua potencialidade de diálogo com campos e disciplinas que exploram o binômio mobilidade-espaço, tais como a Geografia e a Demografia, de forma que seja possível o estabelecimento de nexos interdisciplinares com as ciências sociais.
\end{abstract}

Palavras-chave: Mobilidades Contemporâneas; Mobilidade Espacial da População; Rede Urbana; Interdisciplinaridade.

\begin{abstract}
Based on the mobilities paradigm (The new mobilities paradigm), the article discusses the forms of Brazilian mobilities, highlighting its spatial dimensions. A bibliographical survey was carried out of the primary authors who discuss the theme from the paradigm, as mentioned above, seeking to highlight the spatial dimension of mobility practices. This reflection is linked to data from the 2000 and 2010 Demographic Censuses and other sources, explaining patterns and forms of mobilities that exist in the country. The results point to an increase in the forms of mobilities between 2000 and 2010 and a set of territorial fixed that make virtual and imaginary mobility possible, connecting places and people spatially distant, which makes it possible to establish comparisons of the Brazilian case with other socio-spatial contexts. By bringing to light the mobility paradigm, still little explored in Brazil, we highlight its potential of dialogue with fields and disciplines that explore the binomial mobility-space, such as Geography and Demography, so that it is possible to establish links interdisciplinary with the social sciences.
\end{abstract}

Keywords: Contemporary Mobilities; Population Spatial Mobility; Urban Network; Interdisciplinarity 


\section{INTRODUÇÃO}

O novo paradigma das mobilidades (do inglês New Mobilities Paradigm) surgiu na década de 1990, em um período conhecido como o das viradas epistêmicas nas Ciências Sociais (RODRIGUES; NEVES; ANJOS, 2016). Novos temas e paradigmas entraram na agenda de discussão do campo, servido como uma lente para a interpretação das relações sociais contemporâneas. Autores como Anthony Elliott, John Urry e Mimi Sheller (SHELLER; URRY, 2006; URRY, 2007; ELLIOTT; URRY, 2010; SHELLER, 2017), importantes para a disseminação teórica sobre o paradigma na Sociologia, defendem que as formas de mobilidades (espacial, virtual e imaginária) são fundamentais para compreender a sociedade na contemporaneidade, tendo o conjunto de mobilidades como intrínsecos às relações sociais. O termo "mobilidades" é utilizado no plural para caracterizar uma era marcada pela simultaneidade de acontecimentos nas diversas formas de mobilidade.

As pesquisas dos autores surgiram em um contexto europeu, a partir das pesquisas de John Urry e seu grupo de estudos na Universidade de Lancaster, Inglaterra. Os trabalhos sobre as formas de mobilidades buscam defender a existência de um novo paradigma para as ciências sociais, em que o conjunto de mobilidades seriam basilares para compreender e explicar as práticas sociais contemporâneas. A teoria criada parte do crescente movimento de pessoas, coisas, capital, ideias e informações ao redor do mundo e as consequências para a vida e identidade das pessoas (URRY, 2007; ELLIOTT; URRY, 2010).

Dois principais grupos de críticas são feitas ao paradigma: o primeiro deles é o fato do paradigma surgir em uma realidade socioespacial bem específica, diferente das configurações dos países em desenvolvimento ou subdesenvolvidos (FAIST, 2016); o que demanda uma série de estudos para a adaptação das teorias às diferentes realidades, tendo o conjunto de mobilidades como o eixo norteador da discussão. O segundo grupo de críticas se baseia na ausência do espaço nas discussões que utilizam o paradigma como eixo norteador, bem como a negação de categorias geográficas relevantes (CRESSWELL, 2010), característica relativamente comum nas ciências sociais, as quais vêm gradativamente incorporando o espaço em seus estudos. Publicações recentes buscam justificar e introduzir o espaço geográfico enquanto um elemento importante para explicar e compreender as práticas sociais na era das mobilidades. Como exemplo, o artigo intitulado "From spatial turn to mobilities turn" de Sheller (2017), uma das precursoras do paradigma no qual busca mostrar como o espaço esteve presente em toda construção teórica no contexto europeu.

No primeiro caso, trata-se de uma crítica que ganhou corpo nas últimas duas décadas com o esforço de não apenas contextualizar, mas de descolonizar e de situar o conhecimento. A resistência a teorias formuladas a partir de um ponto neutro (o centro acadêmico e econômico do mundo) ganha corpo no esforço de relativizar teorias que acabam também se tornando instrumentos de dominação 
(CRUZ, 2017). No segundo caso, à primeira vista parece um típico caso de disputa disciplinar entre ciências que almejam justificar sua prerrogativa por meio da centralidade de seu próprio objeto de estudo, o que não é exatamente uma novidade, sobretudo com respeito ao espaço e sua marginalização na história das ciências sociais e, desde os anos 1990, sua retomada naquilo que muitos denominam de "virada espacial das ciências sociais" (BERDOULAY, 1978; SOJA, 1993).

Em vista disso, este artigo procura colocar o novo paradigma das mobilidades (a partir daqui NPM) em questão, no seguimento às duas linhas de crítica. Partimos de um exame de suas proposições sem considerá-lo como uma teoria a ser aplicada. O próprio Urry (2007, p.18) esclarece que utiliza o termo "paradigma" derivado do sentido clássico de Kuhn (1977), buscando estabilizar uma nova pós-disciplina - por ser transversal - que funcione como uma lente para as ciências sociais. Não se trata de construção de uma teoria específica, mas de reunir os fragmentos que já estão entre as perspectivas e diferentes disciplinas, reunindo-as em um mesmo esforço teórico e metodológico. Neste sentido, não se deve olhar para o NPM como um corpus teórico em si, mas como uma demárche que propõe um novo mote para pensar e compreender o mundo contemporâneo no qual a liquidez substituiu a solidez, como as metáforas instigantes de Bauman (2001) nos provocam a pensar este estágio da modernidade.

NPM, portanto, será tomado aqui como este direcionamento que chama atenção para algo que potencialmente pode se mostrar relevante para compreendermos as dinâmicas recentes dos processos de distribuição e redistribuição da população no espaço no Brasil, bem como suas transformações e significados sociais. Isso nos leva à necessidade de compreensão das complexas relações e mobilidades que animam o território brasileiro, em várias escalas, e que apontam para uma outra ordem de intensidade de deslocamentos, bem como seus significados para diferentes âmbitos da reprodução social, da produção do espaço e da experiência geográfica.

Com este propósito, o artigo está estruturado em duas partes: a discussão dos elementos e contexto que sustentam o NPM, buscando fortalecer o seu sentido espacial, seguido do levantamento e análise de dados acerca de fluxos migratórios, mobilidade pendular, fluxos aéreos e dados sobre internet e telefonia móvel no Brasil que permitiriam antever mudanças significativas na intensidade, modos e significados dos padrões de mobilidade no país. Por fim, o artigo aponta para a necessidade do aprofundamento destes debates, de natureza interdisciplinar, articulando-se aos estudos de mobilidade espacial da população e o seu papel no conjunto de "mobilidades" a partir do NPM, buscando situar a discussão no contexto e na realidade espacial do território brasileiro. 


\section{O NEW MOBILITIES PARADIGM}

O NPM está construído no pressuposto de que a contemporaneidade é marcada por ser uma era dotada de um conjunto de mobilidades em que as pessoas estão viajando mais e com rapidez e frequência cotidianamente maior, o que implica em uma mudança na estrutura da vida. Essa nova era traz uma série de possibilidades de reprodução social e, consequentemente, traz uma série de novos riscos cada vez mais imprevisíveis (ELLIOTT; URRY, 2010). A intensidade e o aumento dos movimentos em diversas escalas espaciais, defendem Elliott e Urry (2010), implicam em mudanças no modo como a vida é vivida, experenciada e compreendida. A velocidade de tais movimentos se conecta com a latente vontade pessoal de reinvenção, com uma crítica constante a identidade e a vontade de mudança.

O conjunto de mobilidades contemporâneas configuram-se em três principais categorias: a mobilidade espacial, quando os sujeitos se deslocam espacialmente para outros locais, deslocamentos estes que podem ser cotidiano ou esporádicos; imaginária, por meio do universo de representações afetivas possíveis que os objetos possibilitam e; virtual, com o uso intensivo de dispositivos, sobretudo móveis como smartphones, notebooks e tablets, para a comunicação com familiares e amigos e negócios (SHELLER; URRY, 2006; URRY, 2007; ELLIOTT; URRY, 2010).

Nos Estados Unidos do início do século XIX, os indivíduos viajavam cerca de cinquenta metros por dia (a pé, carruagem ou a cavalo); atualmente, as viagens são de, no mínimo, cinquenta quilômetros por dia de avião ou de carro (ELLIOTT; URRY, 2010). Esse crescente movimento espacial gerou mudanças na identidade, na natureza das ocupações e nas estratégias de vida. $\mathrm{O}$ diferencial desse paradigma se baseia na inclusão da análise das atividades que ocorrem enquanto se está em movimento. Não se trata apenas de uma mensuração dos fluxos, dos motivos e das causas dos movimentos, mas também entender que existe uma sobreposição de mobilidades que atuam concomitantemente enquanto se está em movimento (SHELLHER; URRY, 2006). É a inserção em um conjunto de movimentos materiais e imateriais de difícil dissociação, nos quais um dá suporte ao outro para que possam coexistir.

Tal aspecto é relevante pois alguns estudos sobre os movimentos consideravam o tempo de deslocamento das pessoas como um "tempo morto" em que nada acontece, algo perdido socialmente, em que nenhuma relação social é produzida, seja ela física ou virtual (CRESSWELL, 2010). Esta ideia é muito comum em manuais de trafegabilidade e na mídia cotidiana, quando divulgam os dados que avaliam o "tempo perdido" no trânsito de casa para o trabalho, estudo, lazer. Contudo, observase o oposto. As relações que se dão no período de deslocamento variam de acordo com a forma nas quais as pessoas se deslocam no espaço e sua conjuntura social e econômica. No transporte público, por exemplo, tem-se relações sociais produzidas de forma presencial entre aqueles que se encontram 
cotidianamente na mesma estação de ônibus, metrô ou trem e que fazem o mesmo trajeto. Além dessas relações presenciais, a interpenetração mundo-lugar via tecnologias de comunicação, em especial os smarthphones tornaram a mera presença física quase uma impossibilidade, provocando um radical deslocamento entre corpo e presença.

O NPM contradiz dois conjuntos de teorias: a do sedentarismo e a do fim do espaço com o advento da modernidade líquida. Isto é, as ideias de que o ser humano é sedentário e se movimenta pouco no espaço e de que as relações socioespaciais de afeto (lugar) e poder (território) deixaram de existir (SHELLER; URRY, 2006). A própria ideia corrente de cidade está alicerçada como a forma de habitar sedentário, em contraponto ao anterior nomadismo, o que muitos urbanistas hoje têm colocado em questão (HOLZER, 2017). A máxima neoliberal da dissolução dos Estados, das fronteiras e das especificidades locais, repercutira nos estudos de teóricos que discutiram sobre a falácia dessas dissoluções, mostrando que, com a mundialização das relações econômicas, não ocorreu o fim dos Estados e nem de suas fronteiras (HAESBAERT, 2010). Pelo contrário, os conflitos das sociedades e dos Estados com os movimentos de refugiados de guerra e catástrofes ambientais para países europeus demonstram um aumento nas relações de poder com o espaço, principalmente, no tocante ao fechamento das fronteiras para não acolher os refugiados (MURILLO, 2009).

O paradigma das mobilidades auxilia na explicação da criação das zonas de conectividades e desconectividades. Devido a fatores multidimensionais, existem áreas que são mais conectadas entre si e áreas que são excluídas dessas trocas de fluxos, ou que possuem um menor grau de interação. Tais interações não necessitam de uma continuidade efetivamente espacial, principalmente, pensando nas mobilidades imaginárias e virtuais. Contudo, essa conectividade só é possível se existirem fixos que sustentam os movimentos, sendo necessário que haja um aumento dos fixos em paralelo com o aumento dos fluxos (SHELLER; URRY, 2006). As zonas desconectadas são aquelas em que os fixos e fluxos são poucos, havendo pouca interação espacial, independente da proximidade entre os espaços. Portanto, dialeticamente, para pessoas, coisas e ideias se moverem é e imprescindível que pessoas, coisas e ideias não se movam, sejam imóveis no espaço.

Há diversos tipos de fixos materializados no território, que são entendidos como tal por serem imóveis no espaço, mesmo que desde sua criação tenha necessitado de uma série de movimentos. O primeiro grupo de fixos são as infraestruturas: estradas, cabos e antenas de transmissão, plataformas petrolíferas, entre outras. O segundo grupo que possibilita o movimento de outros, são as pessoas. Para que os fluxos consigam fluir, é necessário que haja pessoas que se movimentem em menor grau, porque abdicaram ou foram forçadas a se movimentarem menos. Nesse grupo incluem os trabalhadores de portos, aeroportos, estações de ônibus e trem, telefonia etc. e, além destes, tem-se na escala familiar o conjugue, pai, mãe, e outras pessoas das famílias que se movimentam menos em prol de um membro que se movimenta mais (SHELLER; URRY, 2006). 
O uso dos termos fixos e fluxos pode reafirmar a dicotomia entre imóvel e móvel e causar uma confusão semântica. Porém, o uso do verbete "fixos" não indica, necessariamente, que os fixos são estáticos nem na sua forma, nem em seu conteúdo e nem em sua função (SANTOS, 1997). Portanto, pressupõe-se que também estejam em um determinado tipo de movimento. Essa ideia caminha para a discussão realizada na Geografia por Santos (1997), pois, para o autor os objetos possuem um conteúdo histórico que lhes são próprios e uma forma física que, com o passar do tempo, podem mudar de função que lhes são atribuídas pela sociedade.

Os fixos possuem movimento, pois, mesmo sendo materialidades, as formas, as funções e os conteúdos, sob um processo histórico de transformação, estão em constantes mudanças materiais (forma) e imaterial (conteúdo e função), ou seja, estão em movimento. Logo, só se pode estabelecer um fixo quando este é relacionado com um fluxo, isto é, só em um contexto onde são determinados quem está se locomovendo e quem não está baseado em um parâmetro determinado.

O movimento é uma característica inerente da sociedade e do espaço. Ambos estão em movimento constante, essencialmente contraditório. Materialidades e imaterialidades estão em um movimento complexo e híbrido, o que torna a sua apreensão apenas um fragmento temporal estático das suas características, no qual busca-se reconstruir.

Nesse sentido, a reconstrução dos fixos e fluxos a partir de frames estáticos do mundo real devem estar inseridas em uma análise que considere o conjunto de objetos e ações, como as pessoas, as infraestruturas e as ações sociais, a partir da perspectiva social, mas também a partir sua dimensão espacial. Portanto, a discussão realizada por Santos (1997), acerca da definição do espaço geográfico como um sistema de objetos e um sistema de ações é apropriada para a compreensão e explicação dos fixos e fluxos apontados no NPM. Pois, segundo o autor, para além de uma comparação direta entre os fixos serem os sistemas de objetos e os fluxos serem os sistemas de ações, Santos (1997) entende que os fixos podem ser objetos tais como as pessoas que atuam, dialeticamente, ora como objetos e ora como ações, o que possibilita uma análise mais complexa e ambivalente das dinâmicas de mobilidades e auxilia. Logo, a rigidez que a palavra fixo traz para a discussão tende a ser tensionada quando entendido a complexidade ambivalente que os objetos possam ter.

\section{A DIMENSÃO ESPACIAL DO NPM}

Os fixos, entendidos como nós de uma rede, são responsáveis por conectar e possibilitar fluxos de mobilidades pelo espaço. Esses nós são fundamentais para que haja fluxos de movimentos, já que são pontos de transferência que agregam os fixos e fluxos tratados anteriormente. Um nó de uma rede de movimentos agrega um conjunto de estabilidades e instabilidades que permeiam os objetos e as ações responsáveis por viabilizar movimentos, haja vista que. O conjunto de nós engloba 
as estações de trem, ônibus e pedágio; aeroportos; hotéis, locais de consumo rápido, bem como os trabalhadores desses espaços e os familiares que se movem em menor grau.

A dimensão espacial dessa relação entre fixos e fluxos deve ser considerada nos estudos, pois, como aponta Haesbaert (2010b, p. 146) “O tempo materializado no espaço interfere diretamente no potencial que os espaços oferecem para transformação e a própria fluidez". O conjunto de materializações viabiliza ou impede os deslocamentos cotidianos na escala regional, sobretudo, dos grupos sociais de menor renda.

Nesse sentido, qual a relação dos sujeitos com os espaços que habitam? A transitoriedade acelerada nos espaços cotidianos implica em mudanças significativas nessas relações, tornando mais fluídas e, como colocado por Augé (2012), sem que o lugar se realize plenamente. Para o autor, que discute o lugar a partir da perspectiva antropológica, uma das características da contemporaneidade é a existência concomitante de lugares e não-lugares.

Os não-lugares dependem de duas dimensões: a primeira composta de fixos criados para certos fins (transporte, trânsito, comércio e lazer) e a segunda abrangendo as relações que os indivíduos possuem com tais fixos. São nesses espaços que as relações de identidade e simbolismo não se realizam plenamente. Porém, como salientado por Augé (2012), não se pode esquecer que os espaços são constituídos de historicidades materializadas, em um acúmulo desigual de tempos como bem lembra Santos (1997). Esse acúmulo de tempo e relações sociais com o espaço que, para Augé (2012) constituiria um lugar, poderiam ter sido realizadas em outros momentos e com outras funções espaciais (SANTOS, 1997). Logo, pode-se dizer que nem os não-lugares se realizam totalmente e nem a historicidade dos espaços são apagados completamente, deixam marcas socio-territoriais. Ou seja, os não lugares só existiriam como um fato completo vendo de forma estática e a-histórica as infraestruturas refuncionalizadas e dotadas de transitoriedade elevadas.

Além disso, a classificação em espaços lugarizados e não lugarizados só é possível pelo olhar do espaço enquanto prática dos lugares. Nesse sentido, o espaço seria constituído apenas de lugares e não lugares, enquanto, outras territorialidades são deixadas de lado. Contudo, os espaços não só apenas práticas de lugarização em diferentes intensidades. Dessa forma, os espaços são justaposição, superposição e sobreposição de diversas territorialidades, sendo o lugar uma delas.

É possível pensar além de lugares e não lugares? Saindo de uma perspectiva antropológica, o geógrafo Yi-Fu Tuan é decerto um dos precursores da discussão de lugar. Segundo o autor, o lugar se diferencia do espaço por ser estruturado: “Dos três termos: espaço, tempo e lugar, o último é o mais concreto, podendo ser traduzido para línguas não europeias sem dificuldades. Lugar é qualquer localidade que tem significado para uma pessoa ou grupo de pessoas" (TUAN, 2012, p.05).

A perspectiva do geógrafo Edward Relph $(1976$; 2012) é mais dinâmica, entendendo a constituição dos lugares a partir de processos de lugarização que conferem diferentes níveis de 
lugaridade. Neste sentido, entre lugares e lugares-sem-lugaridade, haveria uma série de possibilidades de constituição de sentidos de lugar, incluindo a negação, a topofobia, o repelir e, ainda mais importante, a concomitância dos sentidos de lugar, pois não se trata de uma objetividade, mas de uma relação dinâmica, íntima e social ao mesmo tempo.

O lugar pode ser entendido tanto como conceito, como quanto fenômeno da experiência geográfica, dotado de significados particulares e coletivos (RELPH, 2012). Nesse sentido, os significados atribuídos aos objetos são diferentes para cada sujeito. Esses significados são diversos, podendo ser espaços de esperança, de diminuição de vulnerabilidades, de chegadas e de partidas (VIDAL; MUSSET; VIDAL, 2011; FARIA; FALCÃO, 2016).

Esses territórios são diversos e suas interpretações sociológicas, geográficas e antropológicas também o são. Eles variam desde espaços de refugiados, deslocados por problemas ambientais, aeroportos, estações de trem, metrô e ônibus até as paradas de ônibus em uma avenida. Ou seja, atuam em escalas diferentes, tanto cartográficas, quanto geográficas nas redes de fluxos.

Em Mobile Lives, Elliott e Urry (2010) mostram em cada um dos capítulos a rotina de uma família para justificar o paradigma das mobilidades. Ocorre que, além do recorte eurocêntrico de análise, os exemplos são de pessoas com um poder aquisitivo bem diferente da maioria das pessoas que se encontram no Brasil e nos países latino-americanos de modo geral. Os exemplos utilizados são de famílias em que um dos membros possui uma rotina de viagens longas de avião, trem ou mesmo de carro para trabalhar. Pessoas que trabalham com finanças e de alto status social e acadêmico, se movimentam para a manutenção dessas características.

O conjunto de mobilidades implicam em um paradoxo para Augé (2010). Criou-se um mundo em que se pode realizar todas as atividades não circunscritas espacialmente ao cotidiano das pessoas sem que as mesmas precisem se deslocar espacialmente, ainda que se desloquem: os movimentos atuais dos indivíduos não expressam apenas os movimentos espaciais destes. As tecnologias da informação são imprescindíveis para sustentar a ideia de que cada vez mais há uma superação dos obstáculos criados pelo espaço e pelo tempo. Portanto, há um abalo nas fronteiras espaciais e sociais a partir do conjunto de mobilidades que possibilita a conexão com espaços e tempos distintos. Contudo, Augé (2010) argumenta que estas fronteiras nunca se desfazem, apenas são redesenhadas para filtrar os tipos de mobilidades aceitos no interior das suas fortificações (simbólicas e físicas).

Como os próprios autores do paradigma das mobilidades reconhecem, há uma série de críticas a este conjunto teórico que vem sendo criado. A primeira delas é a amplitude da teoria que abarca diversas formas de movimentos e não só os movimentos espaciais (como no caso dos estudos sobre migração ou pendularidade). Para Cresswell (2010), o novo paradigma das mobilidades deve ser visto com cautela e aspectos importantes para a teoria devem ser repensados. A primeira crítica 
do autor, baseia-se na ideia de que os conceitos de lugar, paisagem, território e fronteiras não são abordados da forma como deveriam na teoria, o que pode passar a impressão de que esses conceitos não sejam relevantes para o século XXI. A segunda crítica parte da ideia de que se temos um "novo" paradigma das mobilidades, ter-se-ia um antigo paradigma vigente até um novo corpo teórico tomar conta dos estudos sociais. Qual paradigma seria esse? Um paradigma antigo pautado na imobilidade e sedentarismo? O autor defende que os deslocamentos são característicos da história e, portanto, tem-se que refletir o que há de novo nos atuais movimentos da humanidade (CRESSWELL, 2010).

Na realidade há, se não dois paradigmas stricto sensu, duas posições claras constituídas no Brasil que explicam o processo de distribuição espacial da população: uma que vê o crescimento populacional e o desenvolvimento urbano como resultados do processo de estruturação do capital, no qual se articulam a apropriação e a incorporação de territórios com a demanda por forças de trabalho; e outro que encara o crescimento como algo mais orgânico, próprio das dinâmicas demográficas, ligado à ideia de metabolismo, a partir dos componentes próprios da população.

No entanto, o NPM busca mais do que ser uma teoria explicativa sobre os deslocamentos populacionais ou os processos de mobilidade em geral. Ele, tensiona, como vimos, ao articular os esforços em torno do fenômeno, tal como se manifesta em diferentes contextos. Trata-se de reunir e articular diferentes mobilidades (de pessoas, materiais, ideias, recursos, fluxos, imagens, imaginários) e articulá-las a partir da compreensão de que estes deslocamentos, movimentos e trânsitos estudados cada qual por um setor ou ciência particular, não são eventos desarticulados, mas compõem um todo que permitiria compreender de uma outra maneira as transformações sociais contemporâneas.

Neste sentido, quando nos voltamos para considerar “quão móveis nós somos?”, devemos olhar novamente para diferentes formas de mobilidade, tradicionalmente consideradas tanto nos estudos de distribuição espacial da população quanto de redes e fluxos, visando identificar um sentido geográfico nestas articulações, para além dos próprios recortes disciplinares que, aprioristicamente, fragmentam nosso olhar.

No próximo item, esta questão irá perpassar um olhar a partir da distribuição espacial, permitindo não apenas avaliar as potenciais contribuições do NPM para nosso contexto, mas também identificar desafios que aparecem quando a espacialidade está para além da mera distribuição de pontos e fluxos no território.

\section{MOBILIDADES E DISTRIBUIÇÃO ESPACIAL NO BRASIL}

Entre as mobilidades contemporâneas talvez a mais estudada seja a mobilidade espacial da população. Diversas disciplinas como a Demografia, Geografia, Sociologia e a Economia, buscam compreender os condicionantes e os impactos dos movimentos populacionais (migratórios, 
pendulares ou sazonais) para a estrutura social, espacial, econômica e suas consequências para a saúde, o bem estar e a existência dos sujeitos. Contudo, apesar da vasta bibliografia sobre tais movimentos, o diálogo de tais estudos com o NPM não é significativo, apresentando articulações pontuais.

A mobilidade espacial da população, isto é a mobilidade pendular e a migração, possuem um importante papel na reestruturação do espaço. A migração foi responsável por articular social e espacialmente diversas regiões do país, mudando completamente as dinâmicas demográficas, como no caso das migrações para região sudeste ou a reestruturação urbana ocorrida no estado de São Paulo a partir da década de 1970 (SELINGARDI-SAMPAIO, 2009; SPOSITO; AZEVEDO; 2016). Acompanhada do processo de desconcentração industrial paulista, a migração reestruturou o conjunto de cidades, sobretudo as de porte médio, dando-lhes novas funções e articulações na hierarquia urbana, bem como um aumento populacional maior do que visto nos grandes centros urbanos (BAENINGER, 2004; MARANDOLA JR., 2010).

Além do fluxo de pessoas, tem-se um aumento na movimentação espacial do capital reestruturando o interior paulista e outras regiões brasileiras, a partir da construção de uma série de infraestruturas para viabilizar a instalação das unidades produtivas, bem como a movimentação de mercadorias para outras regiões brasileiras e os portos (SELINGARDI-SAMPAIO, 2009).

Uma das formas de mensurar a mobilidade da população é por meio da migração. Esta entendida como a mudança de um município de origem para outro destino, impulsionado por fatores sociais, históricos, econômicos, ambientais e geográficos (BECKER, 1997). No Brasil, a mensuração desse processo é feita, principalmente, através dos Censos Demográficos em uma escala temporal de cinco anos. Ou seja, a partir da identificação do município em que a pessoa entrevistada residia cinco anos antes (“data fixa”) da aplicação do Censo.

As dinâmicas da população permitem repensar as tradicionais categorias geográficas, sendo a região uma delas. O debate sobre como tais dinâmicas são relevantes para organização do território em nível regional ganhou um ímpeto com a recente publicação do IBGE sobre os Arranjos Populacionais brasileiros, criados a partir das interações entre os municípios tendo como base a pendularidade da população (IBGE, 2015).

A Figura 1 apresenta os fluxos migratórios a partir dos dados do Censo Demográfico de 2010 representando a entrada e saída entre os municípios do país a partir da Data Fixa do Censo de 2010. Cada ponto na figura representa a sede de um município. As cores correspondem a agrupamentos calculados a partir do lugar de cada nó na rede (número de edges e volumes das entradas e saídas por nó/município). Os fluxos migratórios mostraram uma tendência a estarem concentrados em grupos, criando porções de trocas significativas internamente. Contudo, o 
interessante desta abordagem baseia-se no fato de que parte dos fluxos migratórios redefinem a forma de pensar as macrorregiões brasileira tradicionalmente estabelecida.

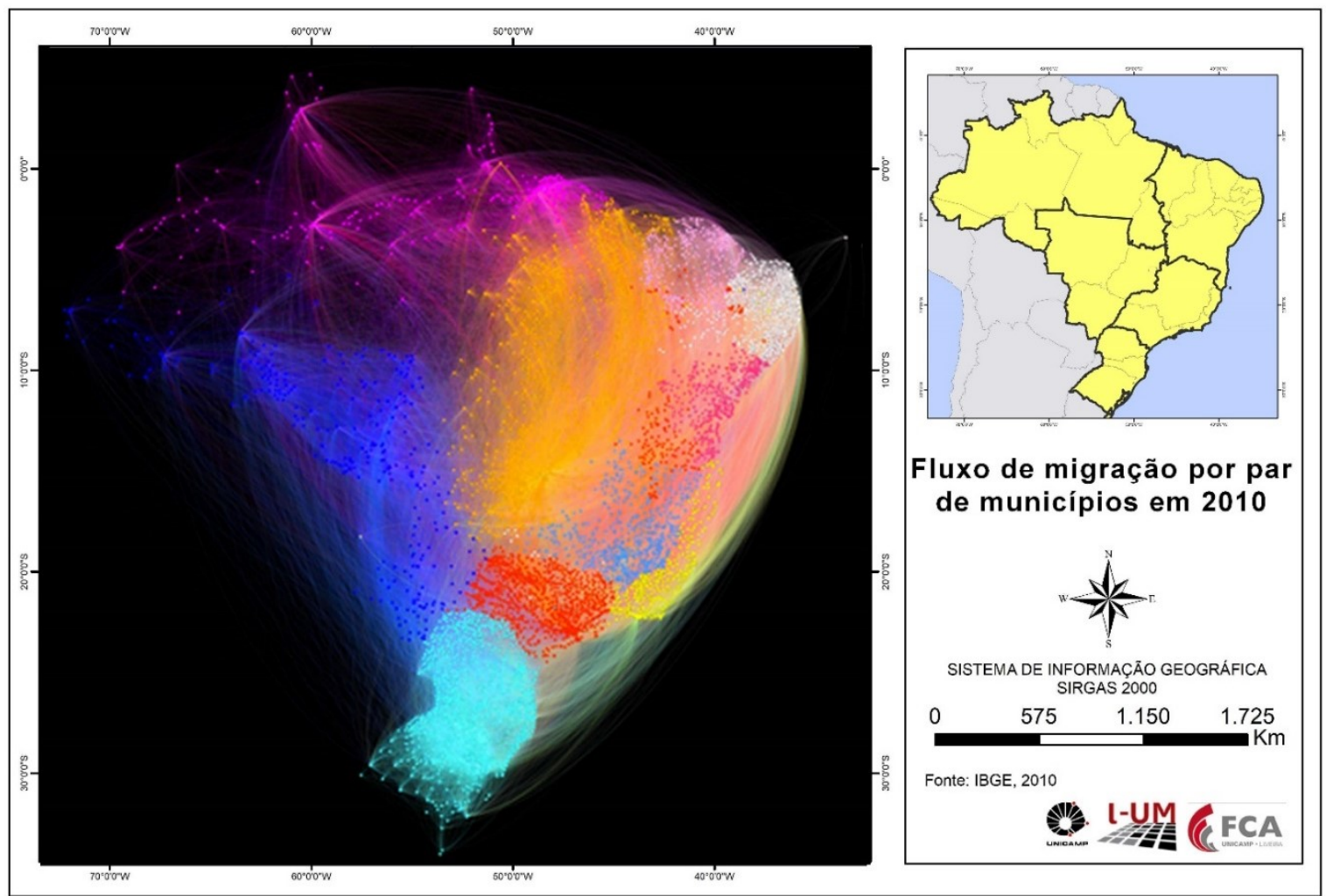

Figura 1 - Fluxo de migração de entradas e saídas entre pares de municípios - Data Fixa em 2010.

Fonte: IBGE, 2013a. Elaborado pelos autores, 2020.

Os agrupamentos calculados e apresentados na figura são resultantes das interações de cada município brasileiro com os demais (volume da população deslocada entre cada par de municípios e o número de trocas de um município com os demais), a partir de uma matriz composta por todos os 5.565 municípios brasileiros. A dimensão espacial dos fluxos não coincide com as macro regiões nacionais - ainda que algumas se aproximem.

Além da migração intermunicipal, os censos capturam também a mobilidade pendular da população, ou seja, as pessoas que trabalham e/ou estudam em outro município sem ser o de residência. Conforme os censos de 2000 e 2010, a população está realizando deslocamentos diários para outros municípios de forma mais intensa em todas as regiões do país. Em 2000, cerca de 7,5 milhões de pessoas trabalhavam ou estudavam fora do município de residência, em 2010 esse número aumentou para 14,5 milhões, ou seja, quase dobrou o número de pessoas que trabalhavam ou estudavam em outro município (IBGE, 2003; IBGE, 2012). Esses dados contemplam a mobilidade pendular e deslocamentos esporádicos como o de saída para trabalhar ou estudar em outra Unidade da Federação, mas mantendo residência no município de origem. Ojima e Marandola Jr. (2012) mostram, a partir dos dados dos censos, como os deslocamentos pendulares aumentaram em todas as 
regiões e classes de cidades, mas especialmente entre pequenos municípios, sem a participação de médias ou grandes cidades, o que ajuda a mostrar um processo de generalização das novas mobilidades.

Do total citado em 2000, 6,5 milhões realizavam movimentos pendulares para trabalho e estudo no mesmo estado, enquanto cerca de 670 mil trabalhavam ou estudavam em outra Unidade da Federação. Já em 2010, dos 14,5 milhões que trabalhavam ou estudavam em outro município, cerca de 10 milhões de pessoas se deslocavam para trabalho. A Figura 2 mostra a estrutura do deslocamento no Brasil, por grandes regiões.

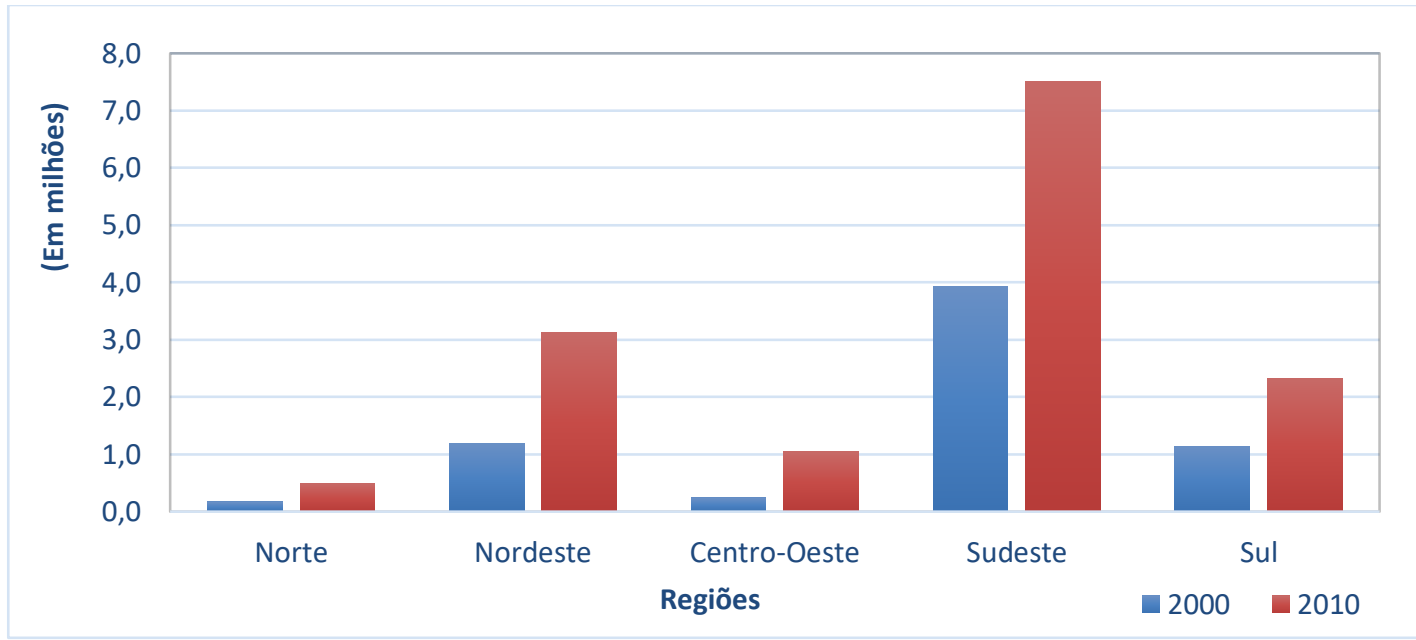

Figura 2 - Total de pessoas que trabalhavam e/ou estudavam em outro município em 2000 e 2010.

Fonte: IBGE, 2002; 2013b. Elaborado pelos autores, 2020.

A região Sudeste é a região que concentra a maior quantidade de pessoas que realizavam deslocamentos cotidianos para outro município tanto em 2000, quanto em 2010, seguido por Nordeste, Sul, Centro-Oeste e Norte. Todas as regiões brasileiras apresentaram um crescimento expressivo no número de pessoas que trabalham ou estudam em outro município, contudo a região Norte a que apresentou a menor taxa de crescimento dentre todas as outras. Ademais, tanto em 2000 quanto em 2010 os homens se deslocavam mais em todas as regiões brasileiras se comparado com as mulheres, tanto para trabalho, quanto para estudo. Porém, tem-se um aumento no número de mulheres que realizam esses deslocamentos se comparado com o ano de 2000 (IBGE, 2002; 2013b).

O aumento da mobilidade pendular é concomitante com o aumento da frota de veículos no Brasil que nos últimos anos foi significativo. Em 2000, a frota era de 29,8 milhões de veículos, aumentando em 2017 para 97 milhões, um crescimento de 325\% (IBGE, 2018). Quando se analisa os automóveis e motocicletas, o aumento entre 2000 e 2017 é de, respectivamente, 265\% e 617\% (IBGE, 2018). As motocicletas apresentaram um crescimento da frota maior que o dobro do aumento de automóveis. As principais causas relacionadas a esse crescimento são o custo de aquisição, manutenção, o baixo consumo de combustíveis e a precariedade no transporte público são. 
Já em relação aos automóveis para cada 100 habitantes no Brasil, o número de automóveis saltou de 17,5, em 2000, para 45,7 em 2017. O mesmo ocorreu com as motocicletas, que saltou de 02 para 10,4, respectivamente (IBGE, 2018). Esse aumento no número de automóveis e motocicletas nos últimos anos é perceptível nas cidades brasileiras, principalmente, naquelas de caráter médio e metropolitanos. Os congestionamentos e o tempo de viagem aumentaram de forma proporcional com o aumento da frota de veículos, bem como os significativos impactos para as cidades e o seu entorno.

Estes dados são substanciais para a reflexão do NPM, já que o imperativo da necessidade de se movimentar cada vez mais, aliado a uma série de fatores específicos do tráfego no Brasil, leva as pessoas a adquirem veículos motorizados particulares, criando um movimento cíclico que resulta na precarização do transporte público e no aumento do transporte motorizado individual. Tal característica está atrelada ao processo de urbanização dispersa do território (MONTE-MÓR, 1994; 2006; REIS FILHO, 2006), isto é, ao processo de urbanização descontínua do território tendendo a criar cidades dispersas e fragmentadas que demanda o uso de automóveis para a locomoção, já que os fragmentos de mancha urbana são criados distantes da área urbana consolidada.

O fenômeno, no entanto, não se limita à circunscrição da mobilidade pendular, a qual está atrelada aos deslocamentos ligados diretamente à estruturação da rede urbana e aos sistemas produtivo e de serviços. No contexto do NPM, mobilidades cotidianas são cada vez mais significativas, as quais implicam uma diversidade de estruturas e padrões não lineares, no tempo e no espaço (MARANDOLA JR., 2011). Para além do estudo ou do trabalho, os deslocamentos se tornam cotidianos por terem por motivo as realizações da vida em um espaço regional, tornado vivido como urbano (MARANDOLA JR., 2014; MARANDOLA JR.; MAGOSSO, 2016). Trata-se de deslocamentos para lazer, para busca de serviços ou mesmo para encontros com os laços afetivos e de segurança que mobilizam a possibilidade do deslocamento para constituir espaços de vida em âmbito regional. Difíceis de serem precisados com dados, estes marcam um novo desafio dos estudos de mobilidade populacional, justamente por revelarem interações espaciais não lineares ou hierárquicas, além de lógicas de mobilidade que escapam a uma racionalidade única.

Nestes casos, a mobilidade pode ser tanto a fuga das limitações e riscos dos lugares quanto a possibilidade de continuar no lugar (ZECHINNATO; MARANDOLA JR., 2012; MARANDOLA JR.; DE PAULA, 2013), em uma ambivalência que aponta para um universo rico que tem sido explorado por diferentes metodologias ainda pouco aplicadas no Brasil, como as que utilizam de dados de telefonia móvel, por exemplo (BUSCHER, 2010; ELLIOT; NORUM; SALAZAR, 2017).

Tem-se, portanto, as diferentes formas de mobilidade estruturando não só o espaço geográfico a partir da possibilidade de um espaço de vida compartilhado entre vários municípios, como também a própria vida das pessoas através da complexa articulação entre espaço, tempo, 
afetividade e mobilidades. Logo, o tema da mobilidade pendular ganha novos contornos em um espaço sem rupturas socioespaciais (DOTA; CAMARGO, 2015).

Os deslocamentos aéreos no país também aumentaram nos últimos anos como pode ser observado pelos dados da Agência Nacional de Aviação Civil (ANAC). No total, há 445 aeroportos registrados e contabilizados até o fim do ano de 2017 (ANAC, 2018). Esses objetos conectam internamente e internacionalmente as regiões do país e esta troca de fluxos está cada vez maior. As Figuras 3 e 4 a seguir apresentam o número de passageiros que viajaram em voos domésticos e internacionais no país.

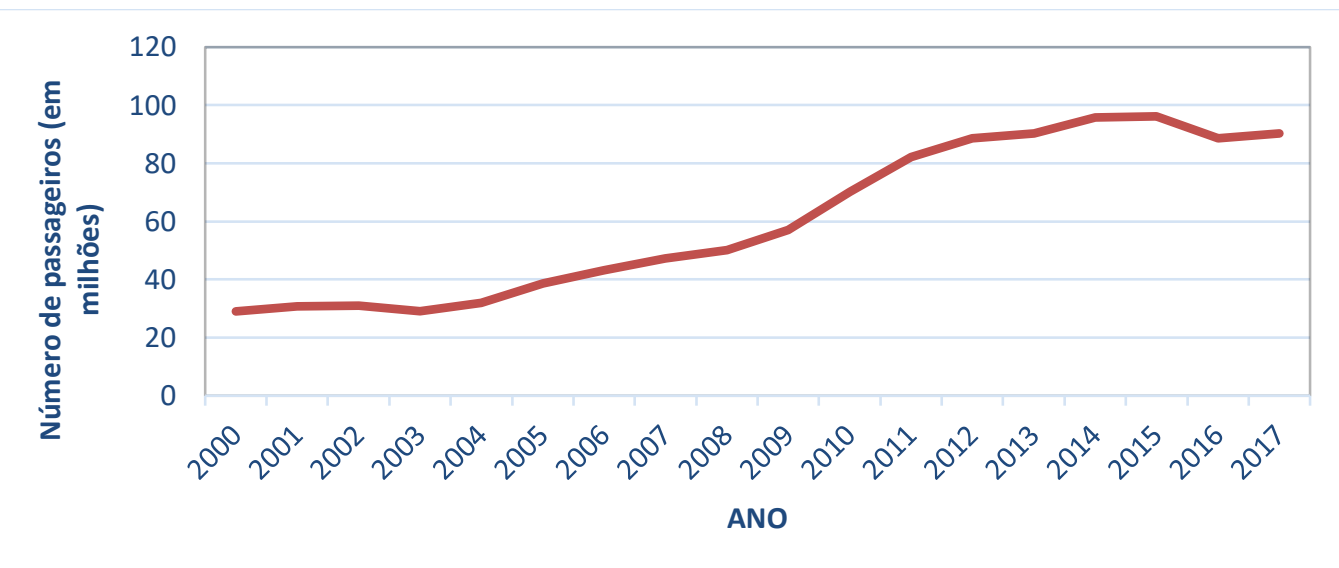

Figura 3 - Número de passageiros pagos em voos nacionais entre 2000 e 2017 (em milhões).

Fonte: ANAC, 2018. Elaborado pelos autores, 2020.

Em relação ao número de passageiros pagos nos voos nacionais, em 2000 o número de passageiros foi de cerca de 29 milhões, aumentando para 90 milhões em 2017. Ou seja, representa um aumento de mais de 300\% nos fluxos de movimentos aéreos. A partir de 2008 observa-se um aumento vertiginoso do número de passageiros e uma queda no ano de 2016. Esta queda se deu, principalmente, pelo momento de instabilidade política e econômica que o país enfrenta ainda hoje.

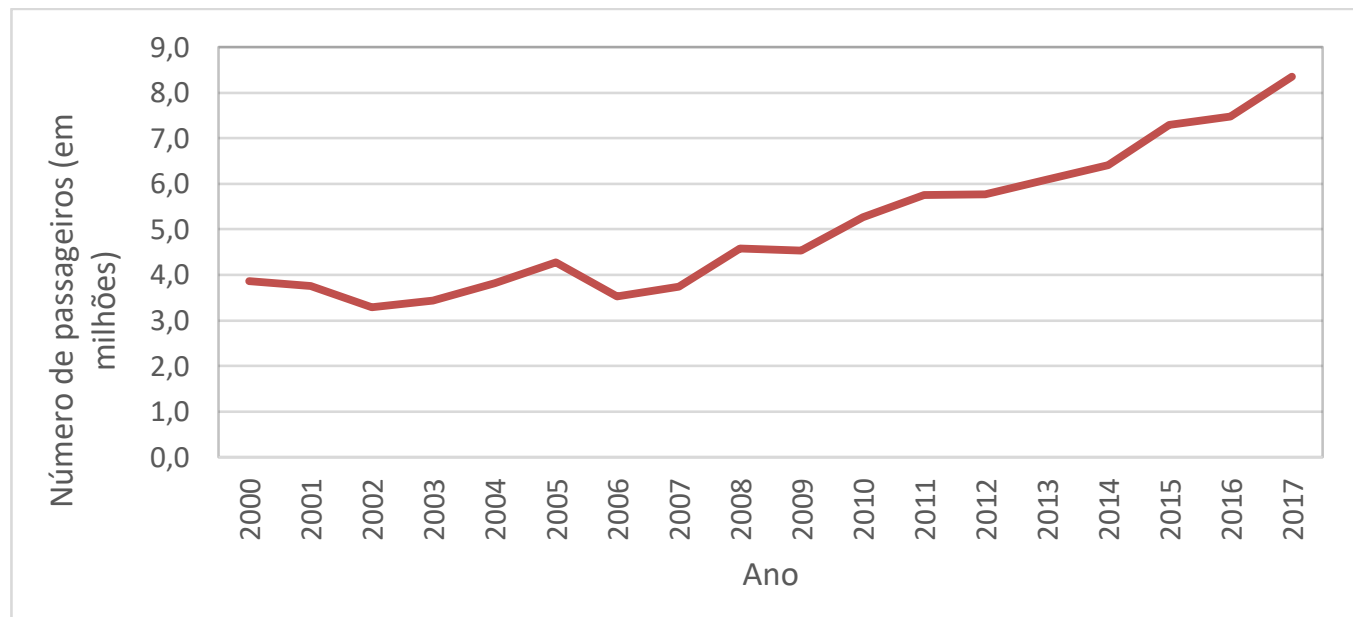

Figura 4 - Número de passageiros pagos em voos internacionais entre 2000 e 2017.

Fonte: ANAC, 2018. Elaborado pelos autores, 2020. 
Comparando os dados de 2000 e 2017, observa-se que o número de passageiros em voos internacionais em 2000 era de cerca de 3,6 milhões, aumentando em 2017 para 8,3 milhões de passageiros, o que representa um aumento de cerca de $215 \%$. Contudo, de forma distinta com o que ocorreu nos voos nacionais, o número de passageiros pagos em voos internacionais não diminuiu em 2016, pelo contrário, aumentou. Tal aumento indica que mais pessoas estão tendo acesso a este tipo de serviço, o que coloca em questão o NPM. Entre 2000 e 2017, a população brasileira cresceu 22,3\%, ou seja, proporcionalmente cerca de 13 vezes menos que o observado nos voos nacionais e internacionais (IBGE, 2017).

Em relação a dimensão espacial dos fluxos, a Figura 5 apresenta os fluxos aéreos entre os principais aeroportos brasileiros em 2008, último conjunto de dados disponibilizados pelo IBGE. Apesar da necessidade de atualização dos dados, o mapa ilustra as conexões entre as principais regiões do Brasil.

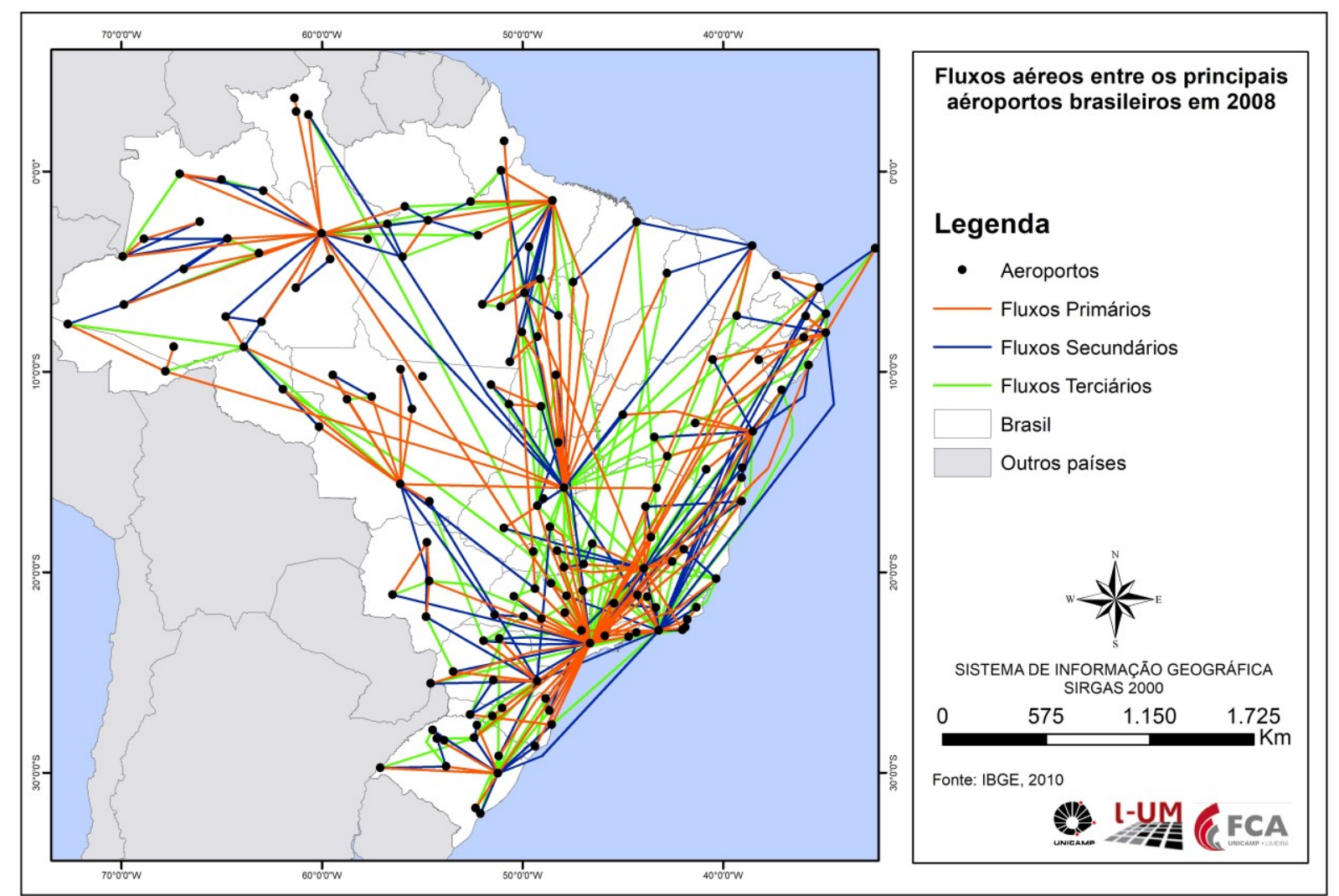

Figura 5 - Fluxos aéreos entre os principais aeroportos do Brasil em 2008.

Fonte: IBGE (2010). Elaborado pelos autores, 2020.

Como apresentado no mapa, São Paulo concentra a maioria dos fluxos, principalmente, os fluxos primários que são os principais na hierarquia adotada pelo IBGE nesse estudo. Observa-se que há pontos nessa rede que possui uma relevância regional na troca de fluxos, como o caso de Manaus que interliga vários pontos na região Norte do país. Em pesquisa realizada em 2014, os aeroportos de 
maior influência, medido pelo número de municípios de origem dos passageiros são, respectivamente, Guarulhos, Campinas, Confins em Belo Horizonte e Porto Alegre (BRASIL, 2017).

Os cinco principais fluxos entre municípios brasileiros encontrados foram: São Paulo e Rio de Janeiro (25\%), Brasília e São Paulo (12\%), Salvador e São Paulo (10\%), Brasília e Rio de Janeiro (9\%) e Porto Alegre e São Paulo (9\%) (BRASIL, 2017). Tais dados reafirmam a importância de São Paulo como capital nacional na hierarquia urbana brasileira (IBGE, 2008), pois, dos cinco principais fluxos, quatro tinham destino/origem o município de São Paulo.

A renda de 21,7\% dos passageiros entrevistados era de 5 a 10 salários mínimos e 18,2\% entre 2 e 5 salários mínimos; entre as motivações para o uso de transporte aéreo, tem-se um equilíbrio entre viagem à trabalho $(49,2 \%)$ e viagem com a família, amigos e parentes para lazer ou evento esportivo e cultural $(45,3)$ e saúde $(2,4)$ (BRASIL, 2017).

$\mathrm{O}$ acesso à internet e o uso de smartphones que é um componente importante para analisar a mobilidade e a imobilidade virtual que, segundo o paradigma, não se dá apenas quando não se está se deslocando espacialmente, mas também, durante o deslocamento. Segundo pesquisas recentes (FGV, 2019), no Brasil há mais de um smartphone ativo por pessoa, totalizando 230 milhões de dispositivos móveis, enquanto a população total era de cerca de 207, 5 milhões. Somando com os Notebooks e Tablets que também viabilizam a interação virtual, são 324 milhões de dispositivos em maio de 2019, isto é, 1,6 dispositivo portátil por habitante (FGV, 2019).

A Pesquisa Nacional por Amostras de Domicílio (PNAD) de 2016 nas Regiões Metropolitanas brasileiras, traz indícios para a reflexão da mobilidade virtual da população. Os resultados encontrados na pesquisa, baseada em uma amostra de 69,3 milhões de domicílios, indicaram que o celular estava presente em $92,6 \%$ do total de domicílios pesquisados, sendo este o dispositivo em que as famílias mais acessam à internet (IBGE, 2018).

Dos domicílios pesquisados $69 \%$ usavam internet e, regionalmente, cerca de $76,7 \%$ no Sudeste, $74,7 \%$ no Centro-Oeste, $71,3 \%$ no Sul, $62,4 \%$ no Norte e 56,6\% no Nordeste. A internet foi mais acessada pelo grupo de pessoas com idade entre 18 a 24 anos e um quarto dos estudantes da rede pública não acessavam a Internet (IBGE, 2018). A Figura 6 apresenta a finalidade do acesso à internet pelas pessoas. 


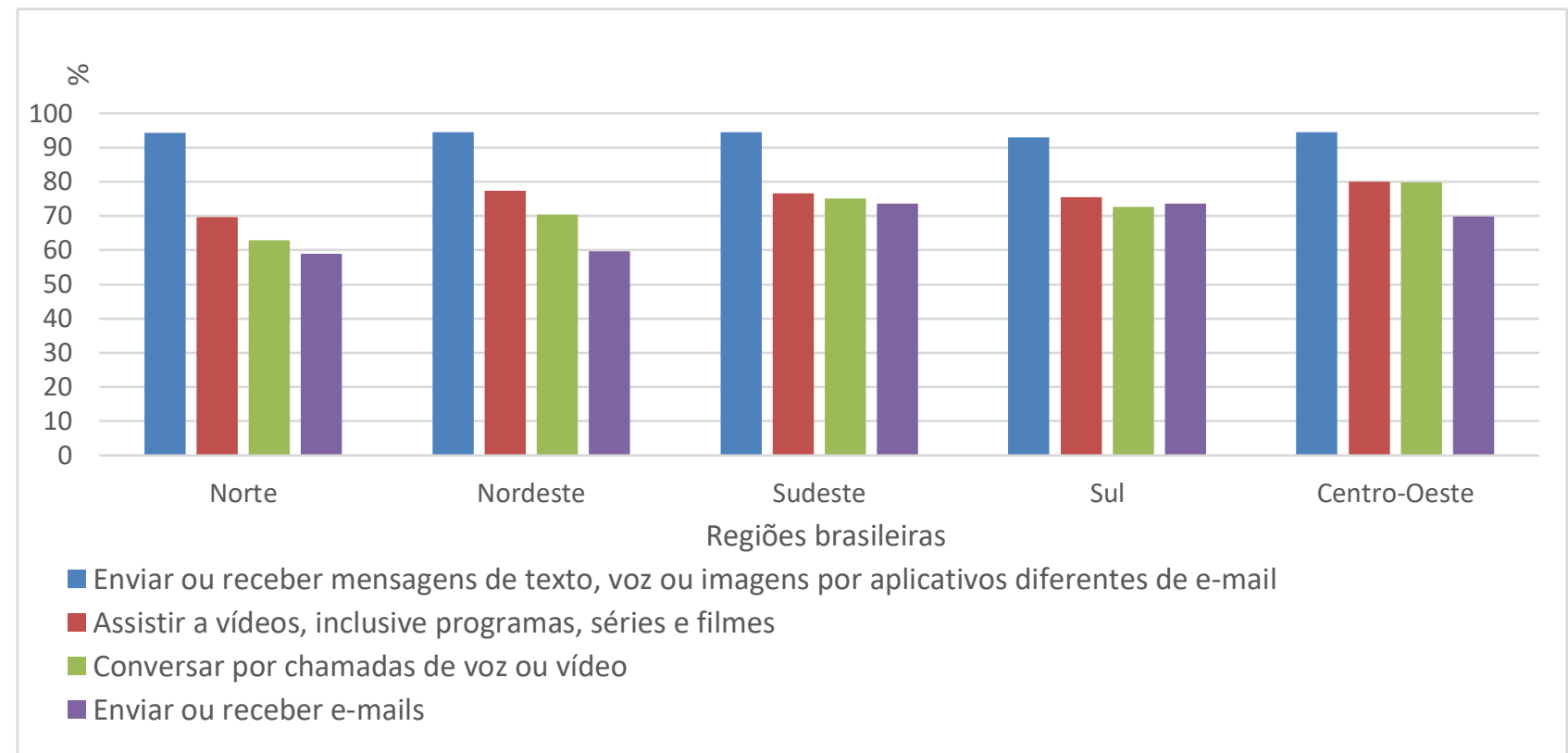

Figura 6 - Percentual de pessoas que acessaram a internet, segundo a finalidade do acesso. Fonte: IBGE, 2018.

As chamadas de voz ou vídeo são elementos que constituem a afetividade com um ente familiar ou amigo destacado por Elliott e Urry (2010), bem como potencializa as transações capitalistas. Elas permitem o contato constante com pessoas próximas afetivamente e, em muitos casos, distantes espacialmente. Para os que possuem uma "vida móvel" (ELLIOTT; URRY, 2010), esse momento de conversa e os equipamentos de comunicações, música, fotografias e vídeos são importantes nos momentos onde a saudade dos filhos, pais, irmãos e amigos. O uso de internet indica a conexão socioespacial quase instantânea, conectando pessoas e espaços distantes, tornando mais complexa a relação espaço-tempo e criando conexões espaciais interessantes de serem analisadas. Ademais, mobilidade virtual e imobilidade acabam por coexistir em uma trama complexa e ambivalente de mobilidades (CRESSWELL, 2010).

Os dados apontam que, no caso do Brasil, é possível pensarmos no NPM no contexto nacional. Porém, cabe verificar se a velocidade, intensidade e quantidade dos movimentos de pessoas, informações, ideias e mercadorias são equânimes em todo o território ou se há áreas que podemos classificá-las por terem movimentos mais lentos do que o contexto nacional.

A informação é peça chave para entender a complexidade da contemporaneidade e a reestruturação do espaço brasileiro. Os objetos técnicos são compostos por um conjunto de técnicas, ciência e informações que em seu arranjo geográfico em nível nacional constitui o meio técnicocientífico-informacional, expressão geográfica do processo de globalização (SANTOS, 2008). A tríade celular - torre - antena como objetos geográficos presentes na paisagem brasileira expressam uma territorialidade informacional (STEINBERGER; TOFETI, 2015). A partir da territorialidade destes objetos, é possível analisar o avanço da tecnoesfera que tem transformado o ambiente natural 
a partir de objetos técnicos (SANTOS, 2008). A Figura 7 é importante para compreender como há uma desigualdade na densidade de fixos que possibilitam a transmissão de informação pelo território.

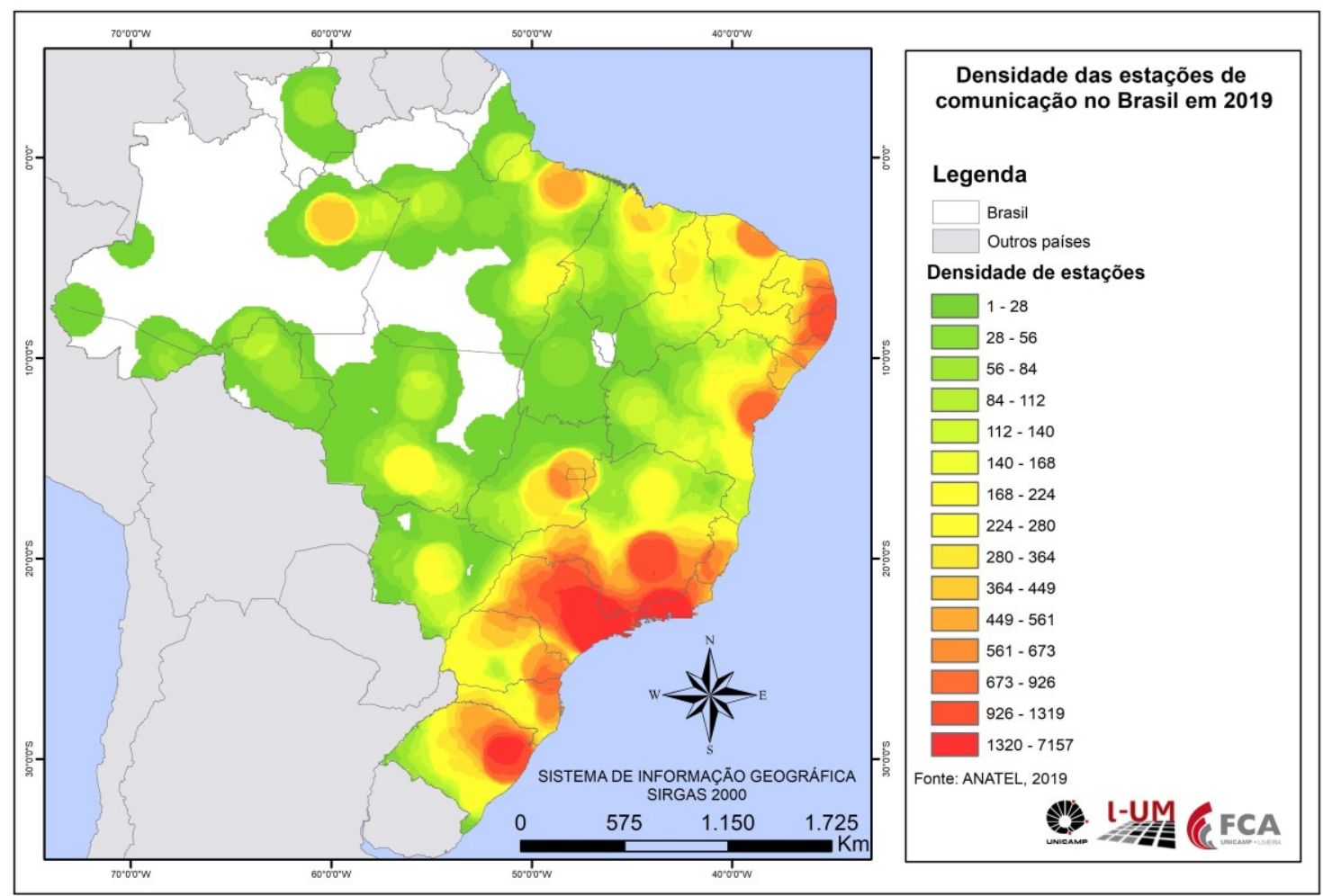

Figura 7 - Densidade das estações de comunicação no Brasil em 2019. Fonte: ANATEL, 2019. Fonte: Elaborado pelos autores, 2020.

Observa-se uma concentração significativa de estações de comunicação na região sudeste brasileira, sendo o estado de São Paulo o que mais apresenta uma homogeneidade na distribuição de estações ao longo do território. As capitais estaduais são núcleos que aglomeram estações de comunicação pela quantidade de pessoas que demandam do serviço; pela concentração de capital nesses espaços e, consequentemente, seu papel na hierarquia urbana regional e nacional. As desigualdades regionais e intrarregionais da disseminação dos fixos de comunicação expressam os processos históricos e geográficos de modernização seletiva do território (BERTOLLO, 2015) que tende a seguir as dinâmicas do capital.

Nesse sentido, pode surgir o questionamento de que são as demandas do capitalismo que reestruturam a paisagem geográfica e não a mobilidade virtual apresentada. Entretanto, no atual estágio da modernidade o acesso à informação está no centro das disputas capitalistas, ou seja, a necessidade de movimentar-se virtualmente no espaço (mobilidade virtual) demanda infraestruturas e, consequentemente, uma transformação da paisagem. Como bem descrito por Santos (2008), o meio técnico-científico-informacional intensificou as interações espaciais através da informação, sobretudo, a viabilidade da informação viajar territorialmente de forma mais rápida, integrando o 
território e criando regiões do mandar e regiões do fazer, isto é, as regiões que emitem ordens para aquelas que as cumprem.

\section{CONSIDERAÇÕES FINAIS}

Com intuito de colocar em questão o NPM e a própria presença das novas mobilidades na tecitura da rede e da vida urbana brasileira demonstradas pelo atual quadro de distribuição espacial da população, em sua dimensão espacial, esse trabalho traz uma síntese das discussões sobre a teoria no campo da Sociologia, buscando articulá-la de forma interdisciplinar com outros campos que discutem espaço e mobilidade, tais como a Geografia, a Demografia e a Antropologia. Os diálogos estabelecidos não se esgotam aqui, ao contrário: o caso brasileiro permite a abertura de um campo importante tanto para questões geográficas, quanto sociológicas de interpretação da contemporaneidade e da comparação com outros países, sobretudo, pelo contexto socioespacial distinto que o Brasil, como país latino-americano, apresenta comparado com os países europeus.

A mobilidade espacial é característica da história humana e, no atual estágio da modernidade, ganha novos contornos e novos grupos de mobilidades, tais como a imaginária e a virtual que coexistem e implicam em práticas sociais. O que é defendido neste artigo é que para além de tais questões sociais, a dimensão espacial é um componente fundamental para a manutenção dessas novas práticas sociais. Dessa forma, o conjunto de objetos e ações criados para a viabilização das formas de mobilidades reorganizam o território conectando lugares, pessoas e capital. Sem a dimensão espacial de análise, que permite refletir qualitativamente e quantitativamente os fixos e os fluxos que viabilizam este conjunto de mobilidades, a interpretação dessa nova conjuntura fica restrita, bem como apontam os críticos ao paradigma das mobilidades, sobretudo, os geógrafos e o seu papel de interpretação das territorialidades dos fenômenos.

Os resultados encontrados na pesquisa apontam para três grupos de temas a serem explorados, sendo o primeiro deles acerca das características da mobilidade espacial, virtual e imaginária da população, observado pelos dados quantitativos dos Censos Demográficos, bem como a partir dos usos que a população faz dos smartphones e da internet. Tais dados contribuem com o pensamento de Sheller e Urry (2006) quando buscam contradizer a teoria do sedentarismo dos seres humanos, pois, permitem identificar um aumento nas formas de mobilidades. O segundo grupo versa sobre a articulação escalar dos fixos territoriais para viabilizar as mobilidades e como esses fixos seguem uma dinâmica histórica de ocupação territorial e demandas de conexão espacial, refletindo sobre como tais fixos e fluxos reproduzem uma lógica de desigualdade espacial existente no país, de forma que seja possível o estabelecimento de correlações com o que vem sendo produzido acerca das mobilidades em outros países com distintos contextos socioespaciais. 
Por fim, o terceiro grupo deve discutir o lugar, explorado inicialmente neste texto, buscando identificar como o lugar se reestrutura nesse período de maior fluidez. Indica-se aqui uma hipótese de que os conjuntos de mobilidades permitem a manutenção de lugar, devido à possibilidade de maior mobilidade espacial, sobretudo em contextos metropolitanos, bem como as mobilidades virtual e imaginária que viabilizam conexões espacialmente distantes.

\section{AGRADECIMENTOS}

Os autores agradecem à FAPESP (número do processo 2016/24641-3) e ao CNPQ (número do processo 312220/2016-2) pelo financiamento da pesquisa.

\section{REFERÊNCIAS}

AGÊNCIA NACIONAL DE AVIAÇÃO CIVIL (ANAC). Número de passageiros em voos nacionais e internacionais - série histórica, 2018. Disponível em: https:/www.anac.gov.br/ noticias/2019/. Acesso em: 27 jan. 2019.

AGÊNCIA NACIONAL DE TELECOMUNICAÇÕES (ANATEL). Estações Licenciadas a Operar nos radioenlaces associados ao Serviço Móvel Pessoal. Disponível em: http://dados.gov.br/dataset/estacoes-licenciadas-a-operar-nos-radioenlaces-associados-ao-servicomovel-pessoal. Acesso em: 27 jan. 2019.

ALVES, C. D.; PEREIRA, M. N.; FLORENZANO, T. G. Mapeamento das novas formas de ocupação urbana por meio da análise orientada a objeto. Estudo de caso: Aglomeração Urbana de Piracicaba. In: SIMPÓSIO BRASILEIRO DE SENSORIAMENTO SEMOTO. 14., 2009, Natal. Anais... Natal: INPE, 2009. p. 569-576.

AUGÉ, M. Por uma antropologia da mobilidade. 1 ed. São Paulo: Ed. UNESP, 2010. 112p.

AUGÉ, M. Não-Lugares: Introdução a uma antropologia da supermodernidade. 1. ed. São Paulo: Papirus, 2012. 111p.

BECKER, O. M. S. Mobilidade espacial da população: conceitos, tipologia, contextos. In: CASTRO, I. E.; GOMES, P. C. C.; CORRÊA, R. L. (Orgs.) Explorações geográficas. Rio de Janeiro: Bertrand Brasil, 1997. p. 319-367.

BERTOLLO, M. A rede de internet sem fio e o smartphone: a capilarização da informação e comunicação nas dinâmicas espaciais. In: ENCONTRO NACIONAL DA ANPEGE. 11., 2015, Presidente Prudente. Anais... Presidente Prudente: ANPEGE, 2015 p. 1-15.

BAENINGER, R. Interiorização da migração em São Paulo: novas territorialidades e novos desafios teóricos. In: ENCONTRO NACIONAL DE ESTUDOS POPULACIONAIS. 14., 2004. Anais... Caxambu: ABEP, 2004. p. 1-14.

BAUMAN, Z. Modernidade líquida. 1. ed. Rio de Janeiro: Jorge Zahar, 2001. 280p.

BERDOULAY, V. The Vidal-Durkheim debate. In: LEY, D.; SAMUELS, M. (Eds.) Humanistic Geography: problems and prospects. Chicago: Maaroufa Press, 1978. p. 77-90. 
BRASIL, MINISTÉRIO DE INFRAESTRUTURA. O Brasil que voa - Perfil dos Passageiros, Aeroportos e Rotas do Brasil. 2017. Disponível em: http://transportes.gov.br/obrasilquevoa/perfildo-passageiro.php. Acesso em: 28 jan. 2020.

BUSCHER, M.; URRY, J. Mobile methods. 1. ed. London: Routledge, 2010. 224p.

CRESSWELL, T. Towards a politics of mobility. Environment and Planning D: Society and Space, v. 28, n. 1, p. 17-31, 2010.

CRUZ, V. C. Geografia e pensamento descolonial: notas sobre um diálogo necessário para a renovação do pensamento crítico. In: CRUZ, V. C.; OLIVEIRA, D. A. (Orgs.) Geografia e giro descolonial: experiências, ideais e horizontes de renovação do pensamento crítico. Rio de Janeiro: Letra Capital, 2017. p. 15-36.

DOTA, E. M.; CAMARGO, D. M. Regionalização, mobilidade pendular e os desafios metropolitanos: o caso da RM de Campinas. Revista Política e Planejamento Regional, Rio de Janeiro, v. 2, n. 1, p. 127-148, 2015.

ELLIOTT, A.; URRY, J. Mobile Lives. 1. ed. Londres: Taylor \& Francis e-Library, 2010. 208p.

ELLIOTT, A.; NORUM, R.; SALAZAR, N. (Eds.) Methodologies of mobility: ethnography and experiment. 1. ed. New York: Berghahn, 2017. 216p.

FAIST, T. The mobility turn: a new paradigm for the social sciences? Ethnic and Racial Studies, v. 36, n. 11, p. 1637-1646, 2013.

FARIA, T. J. P.; FALCÃO, D. A. As políticas públicas criam territórios da espera? O caso do programa Morar Feliz da Prefeitura Municipal de Campos dos Goytacazes (RJ- Brasil). Nuevo Mundo - Mundo Nuevos, v. 1, p. 1-16, 2016.

FREMONT, A. A região, espaço vivido. 1. ed. Lisboa: Livraria Almedina, 1980. 276p.

FUNDAÇÃO GETÚLIO VARGAS (FGV). 30ª Pesquisa Anual do Uso de TI nas Empresas. São Paulo, 2019. Disponível em: https://eaesp.fgv.br/ensinoeconhecimento/centros/cia/pesquisa. Acesso em: 25 fev. 2020.

HAESBAERT, R. Região, regionalização e regionalidade: questões contemporâneas. ANTARES, n. 3, p. 2-24, 2010a.

HAESBAERT, R. Regional-global: dilemas da região e da regionalização na geografia contemporânea. 1. ed. Rio de Janeiro: Bertrand Brasil, 2010b. 208p

INSTITUTO BRASILEIRO DE GEOGRAFIA E ESTATÍSTICA (IBGE). Arranjos Populacionais e Concentrações Urbanas do Brasil. Rio de Janeiro - RJ, 2015.

INSTITUTO BRASILEIRO DE GEOGRAFIA E ESTATÍSTICA (IBGE). Brasil em Números. Disponível em: https://biblioteca.ibge.gov.br/visualizacao/periodicos/2/bn_2018_v26.pdf. Acesso em: 24 fev. 2020.

INSTITUTO BRASILEIRO DE GEOGRAFIA E ESTATÍSTICA (IBGE). Censo Demográfico de 2000: Resultado da Amostra. 2002 
INSTITUTO BRASILEIRO DE GEOGRAFIA E ESTATÍSTICA (IBGE). Censo Demográfico de 2010. 2013a.

INSTITUTO BRASILEIRO DE GEOGRAFIA E ESTATÍSTICA (IBGE). Censo Demográfico de 2010: Resultado da Amostra. 2013

INSTITUTO BRASILEIRO DE GEOGRAFIA E ESTATÍSTICA (IBGE). IBGE divulga as estimativas populacionais dos municípios para 2017. Disponível em: https://agenciadenoticias.ibge.gov.br/agencia-sala-de-imprensa/2013-agencia-de-releases/16131ibge-divulga-as-estimativas-populacionais-dos-municipios-para-2017. Acesso em: 25 fev. 2020.

INSTITUTO BRASILEIRO DE GEOGRAFIA E ESTATÍSTICA (IBGE). Pesquisa Nacional por Amostras de Domicílio (PNAD) de 2016. Rio de Janeiro. 2018. Disponível em: ibge.com.br. Acesso em: 28 jan. 2020.

INSTITUTO BRASILEIRO DE GEOGRAFIA E ESTATÍSTICA (IBGE). Regiões de influência das cidades: 2007. Rio de Janeiro. 2008. Disponível em: https://biblioteca.ibge.gov.br/ index.php/biblioteca-catalogo?view=detalhes\&id=240677. Acesso em: 24 fev. 2020.

HOLZER, W. Ser-na-cidade: por uma arquitetura e urbanismo como lugar. Pensando, v. 8, n. 16, p. 20-32, 2017.

KUHN, T. A estrutura das revoluções científicas. 1. ed. São Paulo: Perspectiva, 1977. 324p.

LEMOS, A. Cultura da Mobilidade. Revista FAMECOS, Porto Alegre, v. 16, n. 40, p. 28-35, 2009.

MARANDOLA JR, E. J. Cidades médias em contexto metropolitano: hierarquias e mobilidades nas formas urbanas. In BAENINGER, R. (Org.), População e cidades: subsídios para o planejamento e para as políticas sociais Campinas: NEPO/Unicamp, 2010. p. 187-207.

MARANDOLA JR., E. J. Mobilidades contemporâneas: distribuição espacial da população, vulnerabilidade e espaços de vida nas aglomerações urbanas. In: CUNHA, J. M. P. (Org.). Mobilidade espacial da população: desafios teóricos e metodológicos para o seu estudo. Campinas: Nepo/Unicamp, 2011. p. 95-115.

MARANDOLA JR., E. Habitar em risco: mobilidade e vulnerabilidade na experiência metropolitana. 1. ed. São Paulo: Blucher, 2014. 248p.

MARANDOLA JR., E.; DE PAULA, L. T. Espaços de vida migrantes: mobilidade e insegurança existencial na Região Metropolitana de Campinas. Geografia, v. 38, n. 1, p. 67-93, 2013.

MARANDOLA JR., E.; MAGOSSO, C. Mobilidade Espacial da População e Regionalização na Região de Limeira (RJ). In: OJIMA, R.; MARANDOLA JR., E. (Org.). Dispersão Urbana e Mobilidade Populacional. São Paulo: Edgard Blücher, 2016. p. 153-178.

MONTE-MÓR, R. L. O que é o urbano, no mundo contemporâneo. 1. ed. Belo Horizonte: CEDEPLAR, 2006. 152p.

MONTE-MÓR, R. L. Urbanização extensiva e lógicas de povoamento: um olhar ambiental. In: SANTOS, M. Território, Globalização e Fragmentação. São Paulo: Hucitec, 1994. p. 169-181. 
MURILLO, J. C. Os legítimos interesses de segurança dos Estados e a proteção internacional de refugiados. Sur, Rev. int. direitos human., São Paulo, v. 6, n. 10, p. 120-137, 2009.

OJIMA, R.; MARANDOLA JR., E. Mobilidade populacional e um novo significado para as cidades: dispersão urbana e reflexiva na dinâmica regional não metropolitana. Revista Brasileira de Estudos Urbanos e Regionais, v. 14, n. 2, p. 103-116, 2012.

OJIMA, R; MARANDOLA JR., E. "Apresentação". In: OJIMA, R.; MARANDOLA JR., E. Dispersão Urbana e Mobilidade Populacional. São Paulo: Blucher, 2016. p. 11-14.

REIS FILHO, N. G. Notas sobre urbanização dispersa e novas formas de tecido urbano. 1. ed. São Paulo: Via das Artes, 2006. 201p.

RELPH, E. C. Reflexões sobre a emergência, aspectos e essência de lugar. In: MARANDOLA JR., E.; HOLZER, W.; OLIVEIRA, L. (Orgs.) Qual o espaço do lugar? São Paulo: Perspectiva, 2012. p. $17-32$

RODRIGUES, L. P.; NEVES, F. M.; ANJOS, J. C. A contribuição da Sociologia à compreensão de uma epistemologia complexa da Ciência contemporânea. Sociologias, Porto Alegre, v. 18, n. 41, p. 24-53, 2016

SANTOS, M. A Natureza do Espaço: Técnica e Tempo, Razão e Emoção. 3. ed. São Paulo: Editora da Universidade de São Paulo, 2006. 392p.

SANTOS, M. Espaço e Método. 1. ed. São Paulo: Ed: Nobel, 1997. 120p.

SANTOS, M. Técnica, espaço, tempo: globalização e meio técnico-científico-informacional. 5. ed. São Paulo: Editora da Universidade de São Paulo, 2008. 176p.

SELINGARDI-SAMPAIO, S. Indústria e território em São Paulo. A estruturação do multicomplexo territorial industrial paulista - 1950-2005. 1. ed. Campinas: Alínea, 2009. 482p.

SHELLER, M. From spatial turn to mobilities turn. Current Sociology, v. 65, n. 4, p. 623-639, 2017.

SHELLER, M.; URRY, J. The new mobilities paradigm. Environment and Planning, v. 38, p. 207226, 2006.

SOBREIA, D. P. A metrópole e seus deslocamentos populacionais cotidianos: o caso do deslocamento pendular na Região Metropolitana de Campinas. 2007. 107 f. Dissertação (Mestrado em Demografia) - Instituto de Filosofia e Ciencias Humanas, Universidade Estadual de Campinas, Campinas, 2007.

SOJA, E. Geografias pós-modernas: a reafirmação do espaço na teoria social crítica. 1. ed. Rio de Janeiro: Jorge Zahar, 1993. 324p.

SPOSITO, E. S.; AZEVEDO, F. F. A disseminação do modo industrial Em São Paulo e no Rio Grande do Norte: o tempo e o espaço em questão. Revista Formação, v. 1, n. 23, p. 133-157, 2016

STEINBERGER, M.; TOFETI, A. R. A trilogia celular-torre-antena como uma expressão da territorialidade informacional no Brasil. Revista Eletrônica Tempo-Técnica-Território, v. 6, n. 1, p. 73-97, 2015. 
TUAN, Yi-Fu. Espaço, tempo, lugar: um arcabouço humanista. Geograficidade v. 1, n. 1, p. 4-15, 2012.

URRY, J. Mobilitites. 1. ed. London: Polity, 2007. 335p.

VIDAL, D.; MUSSET, A.; VIDAL, L. Sociedades, mobilidades, deslocamentos: os territórios da espera. O caso dos mundos americanos (de ontem a hoje). Confins, n. 13, 2011.

ZECHINNATTO, C. L.; MARANDOLA JR., E. Mobilidade populacional na Região Metropolitana de Campinas (SP): interações espaciais na microrregião sul (Valinhos e Vinhedo). Cadernos de Estudos Sociais, v. 27, n. 2, p. 15-37, 2012.

Trabalho enviado em $26 / 02 / 2020$

Trabalho aceito em $21 / 05 / 2020$ 